\title{
La partidocracia uruguaya: tradición y agenda reciente
}

\author{
Gerardo Caetano \\ CLAEH/FCS-UNIVERSIDAD DE LA \\ REPÚBLICA (URUGUAY)
}

\begin{abstract}
Se examina lo más relevante en la historia del sistema de partidos uruguayo hasta su momento actual y la importancia que éste ha tenido dentro del sistema político. El autor plantea los desafíos políticos presentes en el proceso de transformación del que no es ajeno el sistema de partidos.
\end{abstract}

\section{INTRODUCCIÓN}

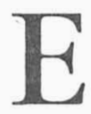

1 presente trabajo aborda el análisis de algunos elementos característicos en el itinerario contemporáneo del sistema político uruguayo. Tomando como centro la acción de los partidos políticos -tópico central de nuestro encuentro y eje temático para establecer luego líneas de análisis comparativo entre los casos nacionales considerados-, mi artículo tratará los siguientes puntos: el señalamiento de algunos de los patrones tradicionales de la política uruguaya de "larga duración"; una visión resumida del itinerario del sistema político uruguayo y en especial de sus partidos en los últimos 40 años; un análisis sucinto de algunos aspectos de la problemática política más reciente en nuestro país. Cabe indicar, por último, que este artículo resume anteriores trabajos del autor, de manera especial dos recientes cuyos títulos son "Partidos políticos y sociedad civil en el Uruguay contemporáneo" y "Bases políticas del desarrollo, en el Uruguay contemporáneo".

La POLÍtTCA URUguaya EN la "LARGa duRACión". AlgunOS DE SUS PATRONES TRADICIONALLS

La consideración del papel decisivo de los partidos en la historia política uruguaya comienza a resultar insosla- 
yable desde el momento en que se intenta diseñar una periodificación adecuada para ordenar su itinerario en la "larga duración". Aunque no es el objeto de esta exposición, cabe mencionar un reciente trabajo de Romeo Pérez titulado "Cuatro antagonismos sucesivos. La concreta instauración de la democracia uruguaya". ${ }^{1}$ Pérez ensaya en él, tomando como punto de partida la hipótesis partidocráti$c a$, un criterio de periodificación especialmente suscitador por sus proyecciones politológicas.

En ese marco, el autor identifica y ubica históricamente lo que califica como los cuatro grandes conflictos articuladores de la democracia uruguaya: a) la pugna entre doctores y caudillos en las primeras décadas del país independiente, que culmina con el resultado de una temprana consolidación de formas protopartidarias y la marginación de los proyectos apartidistas presentes incluso en la primera Constitución; $b$ ) la pugna entre distintos modelos en torno al ejercicio del poder político, que termina con la famosa "paz de abril" de 1872 y el inicio de la llamada "política de coparticipación", que por primera vez estableció de manera categórica la pauta de "admisión recíproca" entre las dos divisas históricas de blancos y colorados; c) la pugna en torno a las modalidades del sufragio y de la representación políticas cuyo epílogo es la consagración de la Constitución de 1919 y la definitiva articulación electoral de todo el sistema político; $d$ ) y, finalmente, la pugna sobre los modos de participación de otros

1 Pérč, "Cuatro", 1988. actores sociales en la vida política cotidiana, que en la década de 1940 prohijó nuevas modalidades de intervención corporativa de sindicatos y cámaras empresariales, aunque bajo pautas de subordinación respecto de la hegemonía partidocrática.

En esta secuencia histórica de "larga duración", que va desarrollando desde los orígenes mismos del Estado oriental hasta la segunda posguerra, se puede observar el itinerario de la configuración de lo que podríamos llamar tentativamente la "cultura tradicional" o la "caja de herramientas" de la democracia uruguaya. A continuación reseñaremos algunos de los patrones más característicos de esa formación política.

\section{Una tradición continuativa}

Constituye ya un lugar común la referencia al carácter estructurado y básicamente estable de la política uruguaya, así como el señalamiento de su fuerte proclividad a la permanencia y a la continuidad. Desde muy temprano, aun antes de su plena configuración moderna, en nuestro sistema político se manifestaron trabas visibles para la irrupción de fenómenos demasiado innovadores (sobre todo en clave drástica y rupturista), facilitándose en cambio la supervivencia continuada de formas, estructuras y agentes de la vida política. Por cierto que la persistencia de estos rasgos -que podría ejemplificarse a través de múltiples fenómenos históricos de muy diversa índole- no puede entenderse como una inmutabilidad absoluta. Antes bien, el caso uruguayo parece 


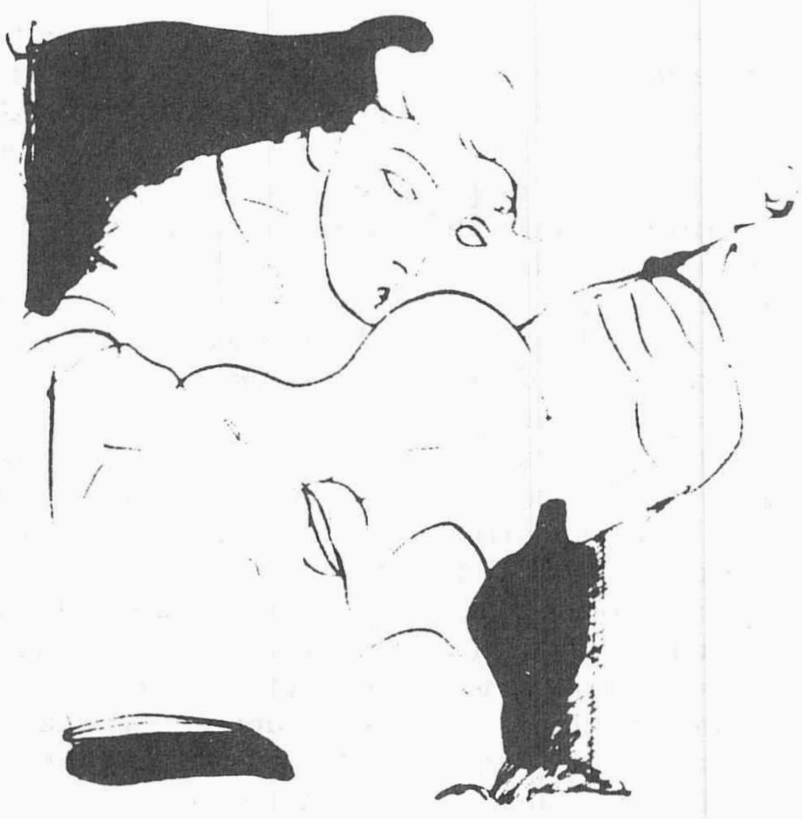

confirmar aquella idea de Easton sobre "la persistencia con cambio y a través del cambio", resultando también muy pródigo en fenómenos de "adaptación por autotransformación" de sus agentes y estructuras. ${ }^{2}$ En el marco del registro de esta política de permanencias, cobra fuerza la pertinencia de referir - sin historicismos ni determinismos- el influjo de un conjunto de características cuyo peso - como veremos- aún parece perdurar en cierto sentido en algunos aspectos de la coyuntura actual.

${ }^{2}$ Easton, "Esqucma", pp. 122 y ss. Para un desarrollo más extcnso y especílico de este problema y su aplicación en la historia política uruguaya, véasc Cactano y Rilla, "Sistema", 1985 , pp. 9 y 55.
Tal vez sea la perdurabilidad de muchos rasgos que definen el proceso formativo del sistema de partidos uruguayos, el ejemplo que mejor ilustre esa tradición continuativa (no disruptiva) de la política uruguaya. ${ }^{3}$ Sin embargo, ésta constituye una caracteristica extensiva al conjunto del sistema político y, en particular, a la dinámica histórica correspondiente a la articulación de las demandas y a la tramitación de los conflictos entre los partidos, el Estado y los actores sociales tradicionales (en especial los sindicatos y las cámaras empresariales).

3 Véasc Cactano y Rilla, "Sistema". 
Una "política de partidos"

$y$ de articulación electoral

El suscrito, en colaboración con otros colegas,${ }^{4}$ ha insistido desde tiempo atrás en el carácter partidocéntrico de la política uruguaya de ayer y de hoy. La postulación de la hipótesis del centrismo de los partidos en un largo proceso histórico destaca el papel decisivo en todo el sistema político de una interacción de partidos permanente, de fuerte identidad y recíprocamente referidos, bajo cuyo influjo se involucra políticamente casi la totalidad de la población del país. Se orienta, asimismo, el suscrito, en la perspectiva de deducir, a partir de esa referencia "partidocrática", implicaciones de historia y de ciencia política. Anotamos algunas de las más relevantes:

a) En un sistema de esas características, los partidos se proyectan como los grandes "vehículos de relevancia", como los "motores-cerebros" de instancias trascendentes, como los sustentos más cabales -aunque no únicos- de toda la formación y de la construcción democrática.

b) Asimismo, su capacidad de acumular aprendizajes reproducibles y la profunda implantación de sus convocatorias y lealtades los hace operar en un escenario con claros predominios sistémicos, lo que redunda en una proclividad a la estabilidad.

c) En el caso uruguayo, esta matriz partidocrática - tan peculiar en Améri-

${ }^{4}$ En particular con Romeo Pérè y José Rilla en el marco del Departamento de Investigaciones del CL.AEH. Véase en particular Caetano, Rilla y Pérez, "Partidocracia", 1987. ca Latina, por otra parte- se asocia con fenómenos distintivos como el de la articulación electoral de todo el sistema, la constante presencia de un Estado inclusivo y relativamente autónomo en sus políticas respecto a los titulares del "poder económico", una cultura política de fuerte impronta liberal, un elenco político estable y con índices relevantes de profesionalización, ${ }^{5} \mathrm{y}$ la debilidad de los procesos de marginación política, entre otros muchos.

En este marco partidocrático de la política uruguaya, globalmente considerado, el espacio efectivo de las relaciones corporativas ha sido generalmente secundario, integrado además en una tónica de reforzamiento de la estructura pluralista del accionar ciudadano. La matriz liberal tan ampliamente implantada redujo el campo de despliegue de los desempeños corporativos, a lo que vino a sumarse la frecuente captura de lo social organizado por los partidos. Existieron además limitantes económicas e histórico-culturales en el influjo de este tipo de actores. En contrapartida, la corporativización de la política uruguaya pudo avanzar - como apuntaremos más adelante- cuando se erosionaron el centralismo del sistema partidario y sus múltiples efectos en términos de cultura política.

5 Para la lectura de estudios históricos sobre los temas del elenco político, sus índices de profesionalización y sus nexos con la dirigencia empresarial, véanse entre otros trabajos: Barrán y Nahum, Batle, en particular el 3o. de sus 8 tomos, titulado "Iil nacimicnto del batllismo"; Cactano y Jacob, Nacimiento, 1989; y para un periodo más contemporáneo, Stolovitch y Rodríguez, "Gobierno", 1987, pp. 163-201. 
Esta relativa marginalidad de los actores corporativos y la proyección segmentaria y debilitada de sus acciones y representaciones no significa que los partidos hayan sido o sean los actores exclusivos de la política uruguaya ni que su acción haya monopolizado la representación integral del conjunto de los sujetos sociales. La centralidad del sistema de partidos no inhibió la existencia de espacios articuladores de gran relevancia entre los desempeños de clave ciudadana y las acciones de cuño corporativo. Más aun, las propias características de los partidos uruguayos y de muchas de sus interacciones más estables han contribuido históricamente a generar un espacio ampliado para la "política de presión", cuyo influjo ha sido muchas veces decisivo en el itinerario de las políticas públicas. Precisamente, la trayectoria del accionar político de los sindicatos y de las cámaras empresariales, muchas veces en el marco de una comunicación exigente, y de ida y vuelta con los partidos, constituye una buena prueba de lo anterior.

Empero, si bien las modalidades de cruzamiento de la política partidaria con la política de intereses (empresariales $y / o$ sindicales) se constituyeron durante décadas en una de las claves configuradoras del rumbo de las políticas públicas en el país, como veremos en detalle más adelante, el Estado privilegió con claridad a los partidos como sus interlocutores reconocidos, tendiendo paralelamente a no transferir ese estatuto a los actores corporativos, en particular en lo que hace a la formulación de políticas generales.
Por su parte, como prolongación casi natural de esa "política de partidos", todo el sistema político se articuló tempranamente en torno a la sucesión de las elecciones. Desde la puesta en vigencia de lá "segunda Constitución" en marzo de 1919, imperó en el país una cultura masiva del voto, sustento del principio general de que los pleitos fundamentales de la sociedad debían dirimirse en las urnas. Sin voto obligatorio, ya en la década de 1920 se registraba en el Uruguay una participación promedio en los comicios cercana al $80 \%$ del total de habilitados, lo que sin duda configuraba un fenómeno llamativo no sólo en el contexto de la región.

Por su parte, a diferencia de lo acontecido en otros países del continente, la ampliación de la participación ciudadana se benefició con los cimientos preexistentes de todo un sistema de lealtades partidarias sólidamente arraigado en la sociedad desde el siglo XIX. En este marco, salvo en situaciones excepcionales y coyunturales, ${ }^{6}$ no ha habido en la historia uruguaya una tradición abstencionista.

${ }^{6}$ Luego del golpe de Estado de 1933, hasta los comicios de 1942 , los principales grupos opositores al régimen dictatorial (los llamados "batllismo neto" y "nacionalismo independiente") se abstuvicron de concurrir a las elecciones en señal de oposición radical. Por su partc, a la salida de la última dictadura militar, los partidos y grupos políticos de izquicrda entonces proscritos valoraron en más de una oportunidad la posibilidad de desarrollar una estrategia dc abstencionismo activo en los comicios que se convocaran. Sin embargo, en las elecciones internas de los partidos habilitados en novicmbre de 1982 , en las que se mantuvo su proscripción, estos grupos resolvicron comparcecr a las urnas votando en blanco. 
Por el contrario, el centralismo del voto ha sido reiterado en forma por demás ostensible como pauta de un amplio consenso institucional.

\section{Un Estado amplio y centralista, en tensión entre la "autonomía" y la "captura"}

Al centralismo partidario, anteriormente descrito en algunas de sus implicaciones, debe sumársele, en una panorámica histórica, la presencia también central del Estado, tempranamente ampliado en sus funciones y en su aparato, preeminente en forma visible respecto de una sociedad civil muy heterogénea, sin impulsos endógenos demasiado vigorosos.

Como han destacado varios autores, ${ }^{7}$ el peso relevante del Estado en la formación política uruguaya tiene mucho que ver con la forma en que se procesó históricamente la delimitación del espacio de lo público y la consiguiente configuración originaria de las relaciones entre Estado y sociedad civil en nuestro país. En este sentido y como ha anotado en particular Franciso Panizza, el Estado uruguayo se constituyó - junto con los partidosen un instrumento de "construcción política del orden social", al tiempo en que también tempranamente emergió como un poderoso "centro imaginario de la unidad social". ${ }^{8}$

El fuerte influjo de esta doble dimensión instrumental y simbólica del

7 Por ejemplo, Panizza, Estado, 1988.

${ }^{8}$ Especialmente Panizza, Uruguay, 1990.
Estado uruguayo se reforzó asimismo a partir de la débil resistencia que encontró este despliegue en el seno de la sociedad civil, lo que estimuló incluso la expansión estatalista a través de su involucramiento en una multiplicidad de funciones que excedían largamente el escenario de lo estrictamente político. Desde la constituciónarticulación del mercado hasta el cumplimiento de una función arbitral en la distribución del poder económico y social, pasando por su participación visible en los procesos de conformación de identidades sociales, la mera reseña de ese espectro amplio de faenas estatales -algunas cumplidas en forma parcial o coprotagónica con los partidos- nos refuerza en este caso la percepción de su preeminencia sobre la sociedad civil.?

En realidad, el centralismo partidario y el estatal se han alimentado recíprocamente en el proceso político uruguayo, contribuyendo ambos a volver "borrosa" la tradicional distinción entre las esferas de lo público y lo privado, así como a consolidar la densidad y el arraigo de las mediaciones más estrictamente políticas. De allí también provienen las bases de un sistema político tradicionalmente incluyente en alto grado, vinculado con una "cultura del arreglo" y del "compromiso", enmarcado en una trama de escenarios dominada por una lógica de vetos y de equilibrios múltiples, a veces enervantes y de complejidad barroca. ${ }^{10}$

\footnotetext{
9) Por un análisis - en clave comparativa con cl caso argentino-de cstc tópico véalsc Cactano y Rilla, "Partidocracia", 1989.

10 Panizza y Pére\% Picra, Estado.
} 
Resulta obvio que en este marco, el Estado uruguayo desempeñó a menudo el papel de un "centro regulador" casi insustituible, con consistencia propia y márgenes de acción relativamente autónomos respecto de las clases dominantes, "más dominantes que dirigentes" de acuerdo con la lúcida interpretación de Carlos Real de Azúa. ${ }^{11}$ A partir de esta peculiar inserción estatal en la sociedad uruguaya, se evidenciaron con frecuencia - aunque también con excepciones- bloqueos estructurales para la adopción de políticas públicas que "representaran" bases clasistas estrechas o excluyentes. La consistencia de la mediación partidaria, la debilidad hegemónica de los actores sociales y la "colonización" de la conducción estatal por un elenco político estable y con índices elevados de profesionalización ${ }^{12}$ constituyeron elementos que reforzaron sin duda esa proyección incluyente, concertante y "no representativa" de las políticas públicas en la mediana y larga duración. ${ }^{13}$

11 Real de Azúa, Uruguay, 1984.

12 Esta tendencia en el elenco político comienza a revertirse a partir de 1959. Véasc Stolovitch y Rodríguez: "Gobierno".

13 Por cierto que esta es una tendencia genérica y de "larga duración", que resultó debilitada en algunos periodos. A este respecto no ocurrió lo mismo bajo cl impulso reformista del "primer batllismo" (1903-1916) que durante el periodo "terrista" (1933-1938) ni fueron asimilables en forma directa las experiencias transcurridas bajo el "ncobatllismo" (1946-1958), los gobiernos blancos entre 1959 y 1967 o cl periodo "pachequista" (1967-1972). A pesar de ello creemos que es visible la persistencia de esta tendencia en una perspectiva histórica de largo aliento.
Pero si el Estado fue en la larga duración relativamente autónomo en sus políticas respecto a los titulares del poder económico, no lo fue en modo alguno respecto a los intereses privados y a la sociedad civil en su conjunto. Antes bien, resulta acertado hablar de una progresiva "captura" del Estado uruguayo por parte de la sociedad civil, convirtiéndose así en el gran "centro institucional de alianzas y compromisos". Como bien han señalado Panizza y Pérez Piera,

más que la estatización de una sociedad civil inerme, [en nuestro país] existió una doble relación de interdependencia, como una tensión permanente entre los actores políticos y sociales que definieron al Estado como un espacio de "plena concurrencia" en su relación con la sociedad. ${ }^{14}$

De esta doble dimensión de "autonomía" relativa frente a los intereses económicos dominantes y de "captura" por parte del vasto entramado de intereses, actores y demandas provenientes de la sociedad civil en su conjunto, emergerá una tensión persistente que "envolverá" la acción del Estado uruguayo durante décadas (en especial entre las décadas de 1930 y 1950), limitando fuertemente su capacidad de productividad política. A este respecto señalan Panizza y Pérez Piera:

Lo público se constituyó [así] más que como la reformulación de intereses

14 Panizza y Pérez Picra, Estado, 1988, pp. 14 y 15. 
particulares en una instancia superior de propuesta y decisión política, como un sistema de mediaciones y agregación de intereses y demandas [...] altamente inclusivo, [en el que se priorizó nítidamente] [...] la articulación de la "voluntad de todos" [...] [sobre] la constitución de la "voluntad general". 15

Por cierto que, como veremos en detalle más adelante, esta manera de concebir la acción del Estado y el espacio de lo público entrará en crisis profunda a mediados de la década de 1950, imposibilitando la reproducción de su "lógica transformista" en una sociedad signada desde entonces por la crisis estructural. De la mano de esa crisis estatal (en un sentido amplio) se producirá también un trastocamiento visible en el "mapa" de las relaciones de los partidos, el Estado y los actores corporativos de la sociedad civil, aunque tampoco faltarán fuertes inercias del viejo "modelo" de articulación política en los periodos siguientes.

Una sociedad civil heterogénea, fragmentada y con dificultades para construir hegemonias

En una perspectiva histórica de largo aliento salta a la vista el rasgo de heterogeneidad estructural de la sociedad uruguaya, reflejado tanto en la complejidad -incluso creciente- de los universos clasistas y del cuadro general de estratificación, así como en una notoria dispersión del humus social perceptible en el terreno de los actores sociales.

15 Ibid., p. 17.
Más allá de ese territorio social caracterizado por la heterogeneidad y la fragmentación, desde comienzos de siglo y merced a los influjos del llamado "primer batllismo", la sociedad uruguaya comenzó a autorrepresentarse en términos de "país de clases medias". Desde el Estado y desde los partidos, desde la política en suma, se tendió a la construcción de un "orden social" caracterizado por la "hiperintegración" y la "amortiguación", cimentándose la vigencia de un imaginario social articulado en torno a los valores del consenso y de la seguridad. Esa configuración de "país de clases medias", producto antes que nada de un proceso de construcción política y cultural, se insertó además en una estructura social sin demasiadas tensiones interclasísticas y con un perfil de "país de cercanías" (al decir de Real de Azúa).

A partir de allí y de la articulación de este cuadro social con el sistema políti$\mathrm{co}$, se vuelve fácilmente reconocible una debilidad hegemónica tan visible como extendida expresada en la ineptitud o imposibilidad de los distintos actores sociales de liderar y dirigir alrededor suyo una configuración hegemónica persistente. Como bien ha señalado Germán Rama a este respecto,

la constante en el tiempo es que ningún grupo con poder económico (o social) fue capaz de constelar a los otros grupos de cúpula y ejercer la hegemonía y la dirección de la sociedad. ${ }^{16}$

16 Germán Rama, Democracia, 1987, p. 120. Francisco Panizza en sus trabajos anteriormente citados ha insistido mucho en esto, desde una posición básicamente coincidente. 
Los fundamentos que explican esa dificultad manifiesta en los procesos de construcción de hegemonía en la sociedad uruguaya son variados y su estudio excede sin duda los límites de este ensayo. Remitamos simplemente algunos factores que guardan una relación particular con el tema que nos ocupa: la debilidad originaria de la matriz corporativa en el país, que se vincula con múltiples fenómenos históricos (el escaso vigor del pasado colonial, la falta de densidad de las separaciones territoriales, la fuerte expansión del imaginario liberal, etc.); los "límites económicos de la influencia corporativa", ${ }^{17}$ que guarda estrecha relación con la fragmentación de la estructura económica local y la relativa dispersión de los grupos económicos dominantes, así como con la propia debilidad general de la implantación capitalista en el país; los bloqueos políticos interpuestos a la posibilidad de un desempeño corporativo hegemónico, lo que remite a temas tales como la relativa ausencia de cohesión y centralidad políticas de los núcleos empresariales, el influjo de la muy temprana configuración partidaria y de la perdurabilidad de su primacía como mediadora y vehículo de consenso e integración, la limitación del alcance político de las prácticas de origen corporativo, etc., entre otros muchos.

Estos rasgos sociales de carácter más general constituyeron un marco

Utilizamos la categoría hegemonía desde una perspectiva afin a la de este mismo autor, Uruguay, 1990.

17 Panizza, Uruguay, 1990, p. 25. fuertemente condicionante para las pautas de desarrollo de las relaciones y prácticas corporativas en la historia uruguaya. Como Jorge Lanzaro ha señalado, el caso uruguayo puede ser así identificado como un ejemplo sólido de corporativismo liberal-democrático, en cuyo marco un pluralismo corporativo pudo asociarse sin mayor violencia con un sistema partidario de efectiva centralidad y amplia implantación social y con un Estado convertido en alojamiento privilegiado de una pluralidad de mediaciones y representaciones de diversa índole. ${ }^{18}$

Es en este sentido que el despliegue de estas modalidades de acción corporativa fue consolidando determinados perfiles en el funcionamiento del sistema político y el arraigo de un conjunto de pautas generales para la regulación de las relaciones entre sociedad civil y política. A título otra vez de simple reseña ilustrativa podrían citarse: una extensión de los poderes estatales que, sin embargo, derivó muy a menudo en una fragmentación decisoria y administrativa muy notables; una compenetración creciente entre lo económico y lo político, una politización profunda de lo social, una creciente confusión de espacios entre lo público y lo privado en el marco de "un continuo juego de diferencias y referencias recíprocas"; 19 una estrategia de acción corporativa que si bien privilegió las modalida-

\footnotetext{
18 Lanzaro, "Empresarios." Del mismo autor véase Neocorporalivismo, 1987

19 Panizza y Pérez Piera, Estado, p. 16.
} 
des de "grupos de presión", también encontró canales de involucramiento más directo y orgánico en el seno del aparato estatal, provocando con frecuencia la recreación institucional de este último; etcétera.

Fue en ese contexto tan marcado por la primacía de la matriz liberalciudadana sobre la matriz corporativa y por la profundidad de la dimensión política en la constitución y resignificación de las identidades colectivas, que se fueron construyendo los cimientos de aquella "sociedad hiperintegrada" como la llamara acertadamente G. Rama, ${ }^{20}$ la que sin embargo tampoco pudo evitar su crisis radical desde mediados de los años 50 .

Es así que una tradición continuadora, una política de partidos y de articulación electoral, un Estado ampliado y central, en tensión entre la "autonomía" y la "captura" y una sociedad civil heterogénea, fragmentada y con dificultades para construir hegemonías constituyen, a nuestro juicio, algunos de los patrones tradicionales que han condicionado más fuertemente la evolución histórica de la política uruguaya contemporánea, el desempeño de sus actores y hasta la fijación de sus pautas de cultura. En mayor o menor medida, el orden político construido en referencia a estas pautas alcanzó su definitiva introducción durante las primeras décadas de este siglo. Del mismo modo, esas pautas políticas y el modelo de desarrollo que sustentaban entraron en crisis ra-

20 Rama, Democracia. dical -aunque con ritmos diversos e impulsos restauradores limitados- a mediados de los años 50, generándose así lo que podríamos llamar el territorio de una ausencia que todavía no ha podido ser cubierta.

En una clave comparativa con la mayoría de los restantes sistemas políticos sudamericanos, no son realmente pocas las singularidades y las especificidades de esta formación política del Uruguay tradicional. Tal vez esa peculiaridad de la política uruguaya en el continente pueda sintetizarse en el registro de su resistencia persistente al establecimiento de experiencias de signo populista neto. En ese sentido, no prosperaron aquí los clásicos liderazgos masivos y extrapartidarios, tampoco los "movimientos nacionales" articulados en la asociación de líderes carismáticos, el pueblo y la nación. En la misma dirección, no alcanzaron arraigo social las clásicas convocatorias dicotómicas que oponían "pueblo vs. oligarquía", ni se estructuró un sistema de inscripción corporativista en el accionar de los actores sociales y en su relación con el Estado y los partidos.

Las inercias de aquella formación política aún sobreviven en su influjo en nuestros días, cuando parece imponerse en el país la necesidad de una reestructuración que poco tiene que ver con el retorno integral -de suyo imposible- de aquella vieja racionalidad política. Sin embargo, difícilmente el proceso de alumbramiento de una "nueva política" en el Uruguay de hoy podrá prosperar y arraigar de modo persistente si se orienta en la perspectiva de una "escisión" 
radical respecto de esa tradición. Como veremos, el problema del cambio y de la reestructuración política así como los requerimientos de un nuevo modelo de desarrollo tienen allí un desafio mayor.

\section{DE LA CRISIS A LA RESTAURACIÓN LIMITADA DEL SISTEMA POLÍTICO TRADICIONAL}

\section{La quiebra del orden político $y$ el despliegue de la "corporativización perversa” (1955-1973)}

El pleno despliegue y la reproducción más o menos exitosa de estas pautas de relación entre los actores de la sociedad civil, los partidos y el Estado no pudieron ocultar - ni siquiera en épocas de normalidad institucional y auge económico- algunas de sus limitaciones intrínsecas. Muchas de ellas alimentaron el impacto en la sociedad y en el sistema político uruguayos de la crisis económica de mediados de la década de 1950, acelerándose así una creciente pérdida de contenido de las formas tradicionales de representación política. El decaimiento institucional y la crisis de gobernabilidad tendieron a confundirse cada vez más con un proceso múltiple en el que se combinaron un curso desafiante a la partidocracia, un desplome en el funcionamiento del "Estado Social" neobatllista y sus lógicas keynesianas ${ }^{21}$ y una creciente corporativización de la

21 La vía uruguaya de construcción del "Estado social" no constituyó la simple traducción política, contrapuesta al viejo modelo "liberal-democrático".

Con todo, los casi veinte años que separan el estallido de la crisis económico-social y la quiebra institucional de 1973 , constituyen una prueba destacable del influjo "amortiguador" de ciertas inercias persistentes de la tradicional formación política uruguaya. En ese sentido, el registro de los inten-

local del auge keynesiano, sino que abrevó también en las acumulaciones de la vicja tradición política del país. $\Lambda$ partir de una recolocación gencral de las prácticas corporativas en el sistema político, ya comenzadas en la década de 1930, en la siguiente se consolidaron diversas experiencias de concertación social que culminaron con lo que Lanzaro llamó "ecuación necobatllista del Istado social". Los rasgos distintivos de esta construcción -seguimos aquí una caracterización del mismo autor-ofrecen una sintesis acabada de la nueva articulación estatblecida: a) Una consagración institucional de la vicja "cultura del arreglo", privilcgiando la "lógica negocial" sobre la productividad polítical y sus opciones más generales. $b$ ) Una profundización de "la compenetración entre el Estado y la sociedad", multiplicándose los armazones insti tucionales de coparticipación con los agentes privados, al punto de consolidarse así la "captura" del Estado por el vasto tejiclo de demandlas c intereses particularistas. c) La extensión de los aparatos estatales y paraestatales, que rápidamente derivó en una acusada fragmentación administrativa y en una disminución de la capacidad de gobierno. d) La ampliación endénicia del burocratismo, debilitándose la idoncidial profesional y las capacidades de gestión acumuladas en algunos casos desde décadas atrís. (e) Por último, la conlirmación del ya anotado giro keynesiano en los particlos, converticlos poco : poco en "agentes de producción y clistribuidores de bienes y servicios públicos, oficiantes de la regulación no mercantil de la economía, síndicos de la reproducción de la fucroa de trabiajo $y$ de la codilicación laboral, todo de acuerdo con la lógica y el balance de poderes del mer. cado político". Véasc Lanzaro, "I:stado", 1990). p. 251. 


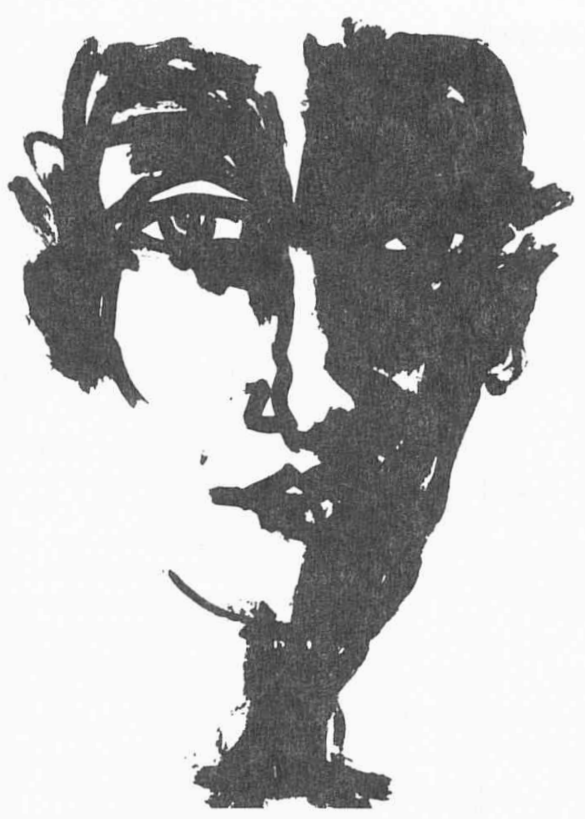

tos de cambio y de desbloqueo protagonizados por los partidos en el periodo $1955-1973$ permite constatar una actividad en verdad impresionante. A este respecto podrían citarse desde la "Reforma Monetaria y Cambiaria" de diciembre de 1959 hasta la experiencia de la Comisión de Inversiones y Desarrollo Económico (CIDE) del primer lustro de la década de 1960 , la reforma constitucional plebiscitada favorablemente en los comicios de 1966 o los realineamientos y las novedades espectaculares que se verifican en el periodo 1958-1973 en el sistema de partidos. En suma, el panorama a este respecto ofrece la imagen de una búsqueda incesante que sin embargo no pudo plasmarse. Aunque con crecientes problemas de productividad política y en medio de un escenario dominado en forma progresiva por una lógica de guerra, los partidos persistieron en su afán de encontrar una alternativa.

La búsqueda de un modelo de desarrollo nuevo ante la convicción generalizada del agotamiento del modelo batllista (al menos en su formulación clásica) fue en efecto uno de los ejes de la política uruguaya en la década de 1960. Durante ese periodo, las políticas públicas puestas en marcha por los sucesivos gobiernos oscilaron entre propuestas neoliberales más o menos dogmáticas y orientaciones de corte desarrollista en diferentes versiones, para culminar en el ajuste autoritario de las administraciones de Pacheco Areco y de Bordaberry que 
antecedieron al golpe de Estado de junio de 1973.

Desde la oposición tampoco faltaron los intentos de renovación programática orientados a evitar (aunque desde distintas perspectivas) el avance de esta lógica de confrontación creciente: merecen destacar a este respecto las propuestas de Wilson Ferreira Aldunate dentro del Partido Nacional y las acciones de diversa índole que dieron origen a la coalición de izquierda Frente Amplio en 1971.

Por su parte, con el telón de fondo de la acción guerrillera del Movimiento de Liberación Nacional (Tupamaros), que estimuló la polarización, y de una conflictividad social creciente que fue reprimida cada vez más duramente, también fueron visibles los esfuerzos de reformulación de modelos en el área de los actores sociales: en este plano, el intento más señalado fue realizado a través de la convocatoria al llamado "Congreso del Pueblo", llevada a cabo por la Convención Nacional de Trabajadores en 1965, hito fundamental del proceso de unificación sindical que culminó con la presentación pública de un "programa de soluciones a la crisis".

Las claves de esta trayectoria política resultan múltiples. El Estado vivió en esos años la crisis de su doble dimensión instrumental y simbólica, quedando crecientemente imposibilitado para tutelar y mediar el orden social y para funcionar como "capitalista colectivo". ${ }^{22}$ Además, su funcionamiento no pudo ya disimular el

22 Panizza y Pérćz Picra, Eslado, 1988, pp. 20 y 21 . agravio de viejos problemas en su estructura, ${ }^{23}$ exacerbados durante el periodo neobatllista y que ahora detonaban por la explosión de demandas antagónicas que ya no podían ser administradas eficazmente. Comenzó también a ponerse en entredicho la centralidad de los partidos, asediados por la irrupción de fenómenos cuestionadores (entre otros, la emergencia de la guerrilla urbana y el incremento de la presencia política de las fuerzas armadas) y por su incapacidad última - pese a sus intentos- para encontrar respuestas sólidas a la crisis y recomponer de modo diferente y eficaz el espacio de lo público. En ese marco comenzaron a proliferar las señales de cancelación del sistema político uruguayo en su configuración tradicional.

Por su parte, lo que ocurrió al mismo tiempo con el accionar político de las cámaras empresariales y de los sindicatos se inscribió dentro de los cambios profundos que terminaron por ampliar, en forma transgresora, el espacio de las prácticas corporativas en la política uruguaya de aquellos años. La imposibilidad manifiesta del Estado y los partidos para canalizar y alojar en su seno las contradicciones y complejidades crecientes de la sociedad uruguaya, dejó el camino libre para una corporativización amplia de la política, de la que participaron-aunque de

23. Lanzaro cita las siguientes: "fragmentación y hasta cicrta obesidad en el organigrama público, policentrismo y autonomización de los procesos decisionales, una penctración de delegaciones sociales que agranda las pesadeces. deficiencias burocráticas". Véase Lanzaro, "lis tado", 1990, p. 253. 
manera distinta - tanto las organizaciones empresariales como las sindicales.

Las propuestas económicas de corte liberal, que comenzaron a desplegarse en el país - con altibajos y bajo distintas modalidades- a partir de 1959, entraron en colisión y se vieron envueltas rápidamente por ese proceso de corporativización política creciente. Las apuestas liberales, además de repudiar la continuidad de los "engranajes keynesianos", reivindicaron una nueva modalidad de productividad política, que junto con el repliegue estatal y la "vuelta al mercado" se vinculaba con un impulso de "descorporativización" y con la primacía de las opciones "generales" sobre los tejidos particularistas. La mayor parte de los actores políticos y sociales, aun aquellos que compartían en el discurso el programa aludido, no pudieron asociarse con las exigencias de esta trayectoria.

El aceleramiento en el proceso de liberalización se vio rápidamente bloqueado: mientras el Estado y los partidos no abandonaban al ritmo previsto sus áreas de intervención, tampoco los agentes económicos empresariales respondian de modo efectivo a la transferencia de liderazgo social que les ofrecían los nuevos gobiernos. Lo ocurrido durante los gobiernos blancos-especialmente en el primero entre 1959 y $1963-$ en sus relaciones con los ganaderos constituye un ejemplo quizá paradigmático de toda esa problemática. $^{24}$

${ }^{24}$ Panizza, "Poder", 1988.
El desafio de la crisis y el viraje en las políticas públicas generó respuestas desde otras tiendas sociales. En este sentido, en el primer lustro de la decáda de 1960 culminaba - como hemos señalado- el proceso de unificación sindical con la fundación de la Convención Nacional de Trabajadores (CNT), central sindical única cuyo nacimiento venía a significar el fin de décadas de dispersión y fragmentación en los sindicatos y que trasuntaba asimismo el peso creciente (impelido sin duda por las décadas de impulso industrializador) del movimiento sindical, tanto en la sociedad civil como en el sistema político.

La crisis era también la de un modelo de "hiperintegración social", 25 que había apostado a la sacralización de instituciones y valores sociales que tenían como supremo objetivo la obtención del consenso y la afirmación de un complejo sistema de garantías y seguridades recíprocas. El estancamiento productivo volvía cada vez más dramática la lucha por el excedente económico, lo que al mismo tiempo ampliaba el espacio para las políticas de presión y debilitaba la tradicional capacidad de articulación social del sistema político y del Estado en particular.

Una reestructuración económica -más allá de su signo- exigía entonces una reestructuración política vigorosa, que al tiempo de terminar con ciertas resistencias y continuidades de la parte caduca de la vieja formación política, ofreciera un nuevo modelo de articulación política verdade-

25 Rama, Democracia, 1987. 
ramente alternativo y viable. Como vimos, los intentos no faltaron ${ }^{26}$ y en ellos pudo percibirse una vez más, aun en la hora de la declinación de su centralismo, una actividad destacada de los partidos en la proposición de temas y agendas.

Por otra parte, aquellos proyectos de reestructuración de signo más o menos liberal de las articulaciones entre política y economía chocaron también con proyectos de signo casi adverso, que en algún sentido se identificaron con una suerte de radicalización planificadora de corte neokeynesiano. En varios sentidos, los planteamientos desarrollistas asumidos parcialmente por el segundo gobierno blanco a partir de 1963 y, sobre todo, algunas disposiciones de la reforma constitucional triunfante en 1966 , se ubicaron claramente en esta segunda perspectiva. Tampoco por esa vía se obtuvo la reestructuración anhelada.

En el marco de una profundización inédita de conflictividad social en el país no pudo encontrarse entonces una respuesta adecuada a esa crisis

${ }^{26}$ Como ya habíamos señalado parcialmente y a simple título de ejemplo de intentos en esa dirección, podrían citarse los siguientes: el cambio de gobierno y el viraje en las políticas públicas a partir de la victoria nacionalista de 1958, la experiencia de la Comisión de Inversiones y Desarrollo Económico (CIDI), los desarrollos programáticos del Congreso del Pueblo en 1965, la emergencia del MI.N, la reforma constitucional de 1967, los cambios y realineamientos en el interior de los particlos tradicionales (la reorientación liberal de la mayoría batllista o la irrupción del ferrcirismo en el nacionalismo), el surgimiento del Frente Amplio, etcétera. profunda de las relaciones entre economía y política. Como bien han señalado a este respecto Panizza y Pérez Piera:

La falta de autonomía y densidad estática del aparato estatal [hizo] que no [existiera] un espacio público consolidado en el cual [pudiera establecerse] la hegemonía del capital, en la medida en que será imposible ocupar en forma estable un espacio caractcrizado por su fragmentación y plena concurrencia. En cuanto al Estado, se mostró incapaz de constituirse en un espacio para la unificación de las diversas fracciones del capital, las racionalidades parciales y contradictorias de sus diversas fracciones impidieron la vigencia de una estrategia de acumulación capaz de superar la crisis del proyecto de sustitución de importaciones del neobatllismo. ${ }^{27}$

Tampoco prosperaron articulaciones hegemónicas alternativas, de base más o menos popular, más allá de los intentos en esa dirección. Todo ello venía a confirmar que ese proceso de "corporativización perversa" de la política uruguaya formaba parte de una crisis más amplia y radical en el tejido de las relaciones entre el Estado, los partidos y los actores de la sociedad civil. La reestructuración política no se produjo, lo que facilitó tanto el decaimiento de la partidocracia uruguaya como el ascenso autoritario de las fuerzas armadas al poder, finalmente culminado con el golpe de Estado el 27 de junio de 1973.

27 Panizza y Pérez Piera, Estado, 1988. 
Dictadura y restauración $(1973-1985)^{28}$

A contramano de lo previsto inicialmente, la dictadura militar que se prolongó por más de una década terminó demostrando una vez más la fortaleza y la capacidad restauradora de la vieja "partidocracia" uruguaya. El autodenominado "proceso" que había comenzado con la denigración de "la política", de los políticos y de los partidos evidenció otro fracaso al culminar su itinerario con las colectividades tonificadas y relegitimadas ante la sociedad civil.

$\mathrm{Ni}$ los entusiasmos neocorporativistas de la primera hora, ni las proscripciones de las elites partidarias, ni las propuestas del candidato único en ocasión del plebiscito constitucional de 1980-, ni la "tentación" del "partido del proceso" lograron borrar las identidades partidarias ni el sistema de lealtades que siempre las nutrió.

La polémica en torno a los partidos y su papel en la "nueva república" ocupó un espacio central en la agenda de los militares y de sus aliados durante los primeros años del gobierno dictatorial. Cuando los aprestos fundacionales comenzaron a percibirse más nítidamente en las filas del régimen, el "¿qué hacer con los partidos?" se

${ }^{28}$ En los análisis que siguen sobre el periodo dictatorial y los tiempos más recientes se tomaron como base los siguientes textos: Cactano y Rilla, Breve, 1987; Cactano, Pérez y Rilla, "Cambios", 1989; Cactano, Rilla, Mieres y P’érez, Partidos, 1992; Caetano, "Partidos", 1992. convirtió poco a poco en una de las interrogantes fundamentales. Si la premisa de la "eliminación" de la izquierda no admitía la más mínima discusión, las dudas surgían en cambio en torno al destino de los "partidos tradicionales". Figuras civiles adictas al régimen (como Alberto Demichelli o Aparicio Méndez) presentaron proyectos de cuño más o menos corporativista, con fuertes restricciones institucionales a la acción de los partidos. El presidente Bordaberry, por su parte, en sus famosas memoranda dirigidos a la Junta de Oficiales Generales entre fines de 1975 y mediados de 1976 propuso la eliminación lisa y llana de los partidos, en el marco de un proyecto de revisión institucional profunda, de claro corte antiliberal.

El tema fue sin duda objeto de intensos debates en el seno de la organización interna militar por aquellos años. Sin embargo, durante la encrucijada de 1976 (apurada incluso por la previsión de elecciones para ese año, de acuerdo con la Constitución de 1966) las fuerzas armadas rechazaron los planteamientos antipartidistas netos y removieron a Bordaberry, manifestando que no querían compartir "el compromiso, la responsabilidad histórica, de suprimir los partidos políticos tradicionales".

Este reflejo tradicionalista en la acción militar también se repitió finalmente en el itinerario de sus posturas respecto al clásico sistema electoral uruguayo. Durante los primeros años, los militares sostuvieron una línea dura y de ribetes principistas contra el viejo régimen electoral del doble voto 


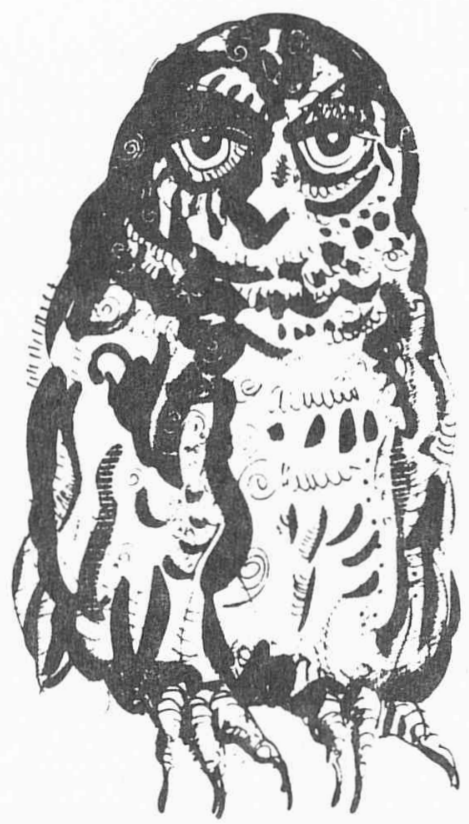

simultáneo (al lema y al sublema). ${ }^{29}$ Sin embargo, tras la derrota de 1980 , tal vez por permeabilidad o pertenencia a la cultura política tradicional, tal

29 El principio del "doble voto simultáneo", establecido inicialmente por la ley del 11 de julio de 1910, ha constituido históricamente uno de los pilares del singular sistema electoral uruguayo, conocido popularmente como "ley de lemas". La fórmula prevé en síntesis la posibilidad de votar a la vez por partidos y candidatos, permitiendo ese voto la acumulación de los sufragios de distintas candidaturas dentro de un mismo particlo o lema. Esta fórmula fuc establecida originariamente por el constitucionalista belga Borely en 1870 y difundida descle lines del siglo XIX por su colega uruguayo Justino Jimćnez de Aréchaga. A pesar de que con posterioridad a la ley de 1910 fueron cambiadas en más de una oportunidad las posibilidades de acumulación, el principio del "doble voto simultánco" ha permanecido firme hasta nucstros clias. vez para ampliar la representación de las minorías oficialistas, alteraron sus convicciones y terminaron defendiendo lo que tanto habian denostado.

El mismo triunfo del NO en el plebiscito constitucional de 1980 puede ser visto çomo una tarea de los partidos políticos, razón por la cual, el nuevo plan militar cayó en la cuenta de que nada era posible sin su concurso. Y en su búsqueda, los militares echaron a andar una ley y un proceso electoral que aseguraran su vigencia. ¿Qué otra cosa se logró sino reforzar las identidades partidarias a partir de la reanimación político-partidaria del 82 ? Piénsese en el frecuente y publicitado funcionamiento de los órganos deliberantes, las convenciones, que mostraron hasta la restauración de los 
"estilos". Piénsese en el ostensible esfuerzo de elaboración y discusión programática, que obligó a saldar al menos una parte de la deuda de "las tradiciones" con "las ideas". Piénsese finalmente en lo que los partidos ganaron en homogeneidad, en explicitación y en capacidad de respuesta a la coyuntura.

La elección de 1984 vino a evidenciar con claridad esa restauración del sistema partidario. Con leves ajustes a nivel de la competencia entre lemas pero con profundos cambios en la correlación de fuerzas al interior de los mismos, todo lo que rodé al proceso electoral de 1984 -aun con sus severas restricciones de diversa índole- vino a significar que los partidos -incluso la izquierda, tan denostada y perseguida durante más de una década- estaban otra vez allí, sobreviviendo a un régimen que había dispuesto de las mayores armas para aniquilarlos.

A diferencia de lo sucedido en otras dictaduras latinoamericanas, el régimen militar uruguayo no logró prohijar la emergencia de actores sociales ni partidos oficialistas. En este sentido se ubican fenómenos como el del fracasado intento de inducir un "nuevo sindicalismo" o un "nuevo empresariado" afines al régimen o la azarosa trayectoria -totalmente frustránea también- del proyecto del "partido del proceso". El general Gregorio Álvarez, último presidente de la dictadura, protagonizó entre 1982 y 1983 el intento más fuerte en esa dirección, recibiendo como respuesta el repudio ciudadano y hasta el rechazo de la mayoría de la oficialidad castrense.

Por su parte, en su relación con los sindicatos, la dictadura uruguaya su- mó al menos tres grandes fracasos. En primer término, el que dejó por el camino, en medio de los ímpetus comisariales de la primera hora, los intentos de reglamentación del movimiento sindical, que más allá de la represión que puso fuera de concurso a muchos militantes y dirigentes suponía su reconocimiento como actor social insoslayable. El segundo fracaso, discernible del anterior en tanto suponía una articulación más específica, evidenció la incapacidad del gobierno militar para sustentarse en algún tipo de organización sindical, "nacionalista" en este caso, que le permitiera además construir un puente con la silenciada sociedad civil. El tercero, al borde ya de la transición democrática, mostró al gobierno atrapado en la dinámica desatada por los resquicios de libertad que debió tolerar, sin poder controlar o moderar siquiera el protagonismo opositor de signo radical de los sindicatos y su restauración como espacios privilegiados para la socialización política hacia la izquierda. ${ }^{30}$

Más allá de su apoyo inicial -más bien tácito que explícito- al régimen militar, y de su respaldo genérico a las pautas de política económica establecidas a partir de 1974 , las cámaras empresariales tampoco llegaron a ser nunca copartícipes efectivas en el diseño de las políticas macro. Éste fue confiado por los militares a un elenco tecnoburocrático de fuerte adhesión a las corrientes neoliberales y sólidos vínculos con el capital transnacional, que en lo posible buscó evitar compromisos exigentes y perdurables con

30 Cactano y Rilla, "Movimicnto", 1988. 
los distintos sectores empresariales. Pese a todo, el peso de las corporaciones empresariales y de sus prácticas persistió durante el periodo, lo que vino a ponerse de manifiesto, sobre todo, cuando comenzaron a hacerse sentir los efectos de la recesión en 1982 y 1983 . Enfrentados entonces con el modelo económico en su conjunto y exigiendo una participación más protagónica en la toma de decisiones, las cámaras retiraron todo apoyo al régimen militar y comenzaron a enfrentarlo con una mayor explicitación pública. ${ }^{31}$

Por su parte, en el proceso de reconstrucción de la sociedad civil operado en forma paralela a la agonía dictatorial, la reactivación de los movimientos sociales tradicionales se dio conjuntamente con la aparición de actores sociales de nuevo cuño, algunos de ellos inéditos en la historia del país. Fue así que comenzaron a cobrar creciente vigor y dinamismo organizaciones como los movimientos cooperativistas de vivienda, diversos movimientos juveniles, movimientos comunales, organizaciones de mujeres, "ollas populares", organizaciones rurales de pequeños y medianos productores, etc., todos con un protagonismo insoslayable en la reconstitución

31 Muchas de ellas intervinicron y se adhirieron oficialmente al "paro cívico" del 27 de junio de 1984. Pese a ello y a sus pronunciamientos opositores en aquel momento, coincidimos con una afirmación de Carlos Filgueira en el sentido de que "el sector empresarial no jugó, como actor sociopolítico, un importante papel en la apertura democrática." Filgucira, Organizaciones, 1988, p. 60 . de la trama social y en la proyección de la lucha antidictatorial.

Sin embargo, y como resultaba en algún sentido previsible, la restauración del sistema político tradicional que signó el proceso de transición desembocó en la extinción, la absorción o por lo menos la pérdida de dinamismo de muchos de estos "nuevos" movimientos que comenzaron a ser progresivamente relegados por la reimplantación de la hegemonía del Estado, de los partidos, y en menor medida, de los sindicatos (con su viejo perfil de "sobrerrepresentación" de los restantes intereses y actores populares).

El trámite final de la dictadura vino a confirmar entonces una transición restauradora, con un retorno vigoroso del partidocentrismo y de aspectos sustanciales del viejo mapa de relaciones entre la sociedad civil y el sistema político. La fuerte electoralización de todo el proceso de salida del autoritarismo viene a confirmar este rasgo.

En efecto, comprobando una vez más el espacio central ocupado en la historia uruguaya por el arbitraje electoral (como referencia incluso configuradora de todo el sistema político), en los últimos cuatro años de la dictadura se convocaron nada menos que tres consultas electorales de índole diversa y con la alteración casi constante de las reglas de juego imperantes: el plebiscito en torno al proyecto de reforma constitucional del régimen en 1980; las elecciones internas de los partidos entonces habilitados (Partido Colorado, Partido Nacional y Unión Cívica) en 1982; y finalmente los comicios generales de 1984. Al 
tiempo de contribuir a la relegitimación de los partidos como actores centrales del sistema político, este profuso calendario electoral que marcó la transición, ratificó la vigencia de un viejo principio en la cultura política de los uruguayos: la de que los pleitos fundamentales debían dirimirse en las urnas.

Lo primero que salta a la vista es en verdad el peso formidable de la tradición electoral sobre el conjunto de los actores sociales. Ni siquiera pudieron sustraerse de su influjo los propios militares, quienes en el momento en que buscaban una legitimación para sus planes fundacionales no dudaron en procurarla por la vía plebiscitaria en 1980, aunque cometiendo el grave error de prescindir de los partidos en su apelación al respaldo ciudadano Por su parte, los partidos, como era absolutamente previsible, centraron progresivamente sus respectivas estrategias hacia las elecciones nacionales de noviembre de 1984 , demostrando una vez más su probada eficacia en el juego complejo de la "alquimia" electoral. También la izquierda -la "convidada de piedra" hasta el último instante- focalizó la tarea de reafirmar su identidad, tan asediada a través de su recomposición en 1984 como actor electoral protagónico.

Sin embargo, pronto se pondría de manifiesto el carácter limitado de esta restauración política. Los desafíos del periodo posdictatorial -que entre otras cosas incluían la culminación de una transición inconclusa y la tarea de impulsar a distintos niveles reformas impostergables- habrían de ratificar una vez más el agotamiento de mu- chas de las lógicas del sistema político tradicional y la persistente exigencia de una reforma política profunda.

\section{La posdictadura (1985-1994) ${ }^{32}$}

Con el estímulo que significa una reflexión finisecular, con la cautela que impone el tratamiento histórico del pasado más reciente y con el agregado además de estar realizando esta exposición en medio de una campaña electoral marcada por la incertidumbre debemos decir que sobran en todo caso los motivos para reconocer en los últimos diez años la sucesión de un conjunto de verdaderos hitos de la historia uruguaya contemporánea. Señalemos a título de ejemplo algunos de ellos:

a) La secuencia de dos administraciones de distinto color político (la colorada del Dr. Julio M. Sanguinetti entre 1985 y 1990 , y la nacionalista del doctor Luis A. Lacalle desde 1990 a la fecha), con todas las implicaciones que supone la rotación de los partidos en el gobierno, en un país de tendencias históricas tan estables. Esta rotación de los partidos no derivó sin embargo en "gobiernos de partido". Cabe decir, con todo, que tampoco podía hacerlo, dada la fragmentación de fuerzas en el sistema partidario.

b) El arduo proceso vinculado al enjuiciamiento de los responsables de la violación de los derechos humanos durante la dictadura militar, jalonado por los intensísimos conflictos en torno a la "ley de caducidad de la preten-

$$
32 \text { Cactano y Rilla, "Historia", } 1994 .
$$


sión punitiva del Estado" de diciembre de 1986 (calificada como "ley de impunidad" por sus impugnadores), y culminado en el referéndum de 1989 , con la aceptación de la misma por la ciudadanía.

c) La sucesión de problemas de gobernabilidad, desde el fracaso relativo de la Concertación Nacional Programática (CONAPRO) hasta las fuertes restricciones para la configuración de un efectivo gobierno de mayorías (ni el intento de la "entonación nacional" de Sanguinetti ni la "coincidencia nacional" de Lacalle pudieron serlo de manera efectiva y perdurable).

d) El incremento de competitividad en el sistema de partidos, traducido en los cambios espectaculares de la voluntad ciudadana en los comicios nacionales de 1989 , que entre otras cosas posibilitaron el acceso del Frente Amplio a la titularidad del gobierno municipal de la capital Montevideo y el establecimiento de una experiencia de cohabitación por muchos motivos inédita en la historia del país.

e) La firma en marzo de $1991 \mathrm{del}$ Tratado de Asunción, cuya finalidad de acelerar la configuración de un nuevo espacio económico integrado en la región (el MERCOSUR), colmó la agenda pública de los principales agentes económicos y sociales, mereció la adhesión unánime de todos los lemas partidarios y el voto conforme de casi la totalidad de los legisladores.

f) La profundización de un conjunto de debates reformistas referidos a ciertas áreas centrales en el quehacer nacional, simbolizada de manera muy especial en la disputa sobre la "ley de empresas públicas" y la reforma del
Estado, aprobada por estrecha mayoría en el Parlamento y luego rechazada en forma contundente por la ciudadanía, en el plebiscito -otra vez- de diciembre de 1992.

g) El fracaso reiterado de distintos intentos de reforma constitucional, algunos de ellos (como el de la llamada "maxirreforma", que incluía un espectro amplio de modificaciones a distintos niveles) bloqueados en el escenario de la negociación interpartidaria y otros (como el de la llamada "minirreforma", centrada más específicamente en los tópicos del régimen municipal) rechazados abrumadoramente por el cuerpo electoral en el plebiscito del 28 de agosto de 1994.

Obsérvense también algunos rasgos de la estructura y de la evolución de la sociedad en este periodo más reciente. Como lo probó en forma categórica el último censo nacional de 1985, la población uruguaya siguió mostrando un crecimiento muy lento (menos de $1 \%$ acumulativo anual), al tiempo que se reforzaban las tendencias de envejecimiento (los mayores de 65 años constituyen $10 \%$ del total). Mientras tanto, la población económicamente activa se incrementó en forma notable, en especial por la creciente participación de las mujeres en el mercado laboral (Uruguay alcanzó a comienzos de los ochenta la tasa bruta de actividad más alta de América Latina). Sin embargo, en su conjunto el mercado de trabajo consolidó un escaso dinamismo, con tasas fluctuantes (pero importantes) de desempleo. En suma, cualquier ejercicio de carácter prospectivo debería tomar en cuenta algunos de los rasgos siguientes, reco- 
nocibles en la historia y presumiblemente estables: debilísima presión demográfica, alta propensión emigratoria, debilitamiento relativo del espacio demográfico uruguayo respecto a las áreas contiguas pertenecientes a los países limítrofes, estructura de edades con la tasa de sobrevivencia más alta del continente, elevado nivel de urbanización y concentración poblacional, etcétera.

A la vez, la distribución del ingreso y del bienestar resulta hoy por demás heterogénea. Durante la dictadura militar se produjo una fuerte concentración del ingreso por la reducción del salario real. Desde la democratización, en especial por la recuperación lograda en sus primeros años, el panorama de desigualdad resulta algo menor. No obstante ello, en Montevideo y en las capitales departamentales cerca del $20 \%$ más pobre de la población recibe alrededor de un $6 \%$ de los ingresos familiares totales, mientras que el 20\% más rico se apropia del $45 \%$ de los mismos. En esa misma dirección, de acuerdo también con un análisis de datos del censo de 1985, más del 22\% de los hogares del país no pueden satisfacer sus necesidades básicas (28.5\% en el interior y $14.6 \%$ en Montevideo).

Sobre estos perfiles generales, algunos actores sociales han demostrado en estos últimos años modificaciones señaladas respecto a sus comportamientos tradicionales. Luego de haber cumplido un papel político relevante en la fase terminal de la dictadura y una vez alcanzada la recuperación institucional, la central sindical no ha terminado de procesar su reestructuración (que va de la recomposición de los equipos dirigentes a la redefinición del carácter de los sindicatos en los nuevos contextos), aun cuando en sus filas se han vuelto visibles (en medio de conflictos no zanjados) diversos intentos en la formulación de diagnósticos novedosos y propuestas independientes más allá de lo defensivo.

Por su parte, los llamados "nuevos movimientos sociales", que aparecieron con una fuerza destacada en los últimos años de la dictadura, han ido perdiendo con la democratización mucho de su poder de convocatoria e inserción. Mientras tanto, aparte de realineamientos y recomposiciones varias, las organizaciones empresariales han mantenido en general sus pautas de comportamiento más arraigadas, en especial en su relación con el Estado. De todos modos, cabe consignar que junto a la profundización de las políticas aperturistas y los crecientes desafíos de la integración regional y el avance tecnológico, han comenzado a constatarse en los últimos años tensiones y debates de importancia en el seno de todas estas organizaciones.

En el plano político, la transición democrática que procesó el Uruguay más definidamente después de las elecciones de noviembre de 1984, mostró que el país se había cerrado al exterior justo en el momento en que el mundo experimentaba cambios vertiginosos, tanto en la ciencia, la tecnología y la producción como en la distribución del poder mundial y en la capacidad ordenadora y explicativa de las ideologías. Todo ello tendría obviamente consecuencias en las formas que adquirió la misma transición, en la experimentación de mecanismos 


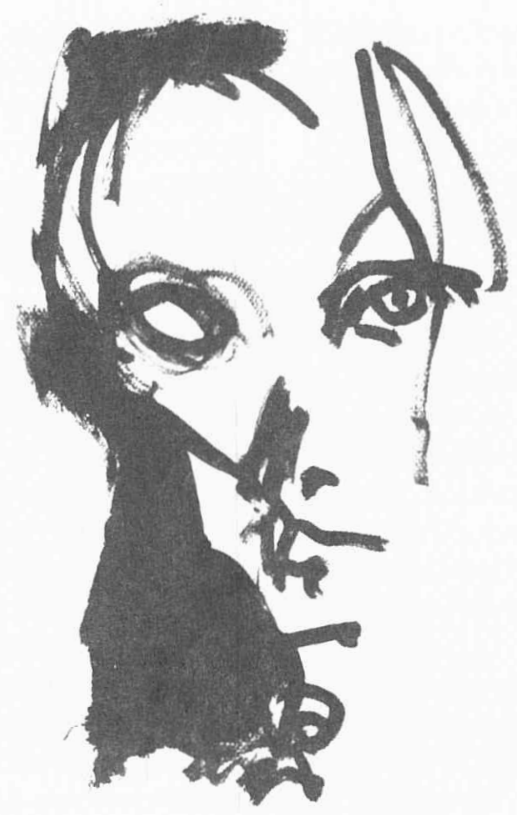

de relación con la economía y el mundo, en los debates políticos ciudadanos.

Sin mengua de las novedades que desafiaban al país en esta "doble transición" (es decir, la puesta al día con sus tradiciones democráticas y con el mundo), muchos de los problemas y tensiones, muchas de las soluciones y bloqueos confirmaron tendencias de larga duración que operaron tanto de garantía estabilizadora del sistema, como de obstáculo en ocasiones fuertemente paralizante.

Adviértase en primer lugar y como una orientación algo inédita y tal vez plausible en América Latina, que la transición pareció confirmar -como ya hemos señalado anteriormente- el partidocentrismo y la articulación electoral de la política uruguaya. En tanto que la "salida" de la dictadura fue pactada y electoral, requirió de la iniciativa y de la conducción de los partidos, los que rápidamente-como vimos- aprontaron su carrera hacia las urnas y ganaron para su dinámica a buena parte del importante esfuerzo que la sociedad civil había desplegado en los tramos finales del proceso militar.

Aunque con algunos altibajos, tal tendencia fue luego ratificada durante las siguientes administraciones democráticas: el trámite de las políticas de concertación, los itinerarios de la impugnación de la "ley de caducidad" o la misma trayectoria de las polémicas sobre la "reforma del Estado" constituyen buenos ejemplos en esa dirección. Sin desmedro de ello, en los 
últimos tiempos el sistema de partidos parece estar perdiendo predicamento y capacidad de iniciativa en la sociedad uruguaya, con una opinión pública que ha venido reiterando sus señales de independencia respecto a los designios de los líderes partidarios. Episodios como el del pronunciamiento plebiscitario del 28 de agosto de 1994 o el propio trámite de la última campaña preelectoral -todavía en curso cuando escribimos estas líneas- proyectan evidencias importantes respecto a un gradual debilitamiento de las lealtades partidarias. De todos modos, la pérdida de poder de los partidos no parece estar acompañada aún de un proceso paralelo de reforzamiento de actores extrapartidarios que puedan presentarse como alternativas viables en términos de conducción política y gubernamental. Sin embargo, parecen cada vez más profundas las limitaciones de la restauración política que acompañó la transición democrática.

Por su parte, la mutación vigorosa que los comicios de 1989 significaron en la historia electoral vino a consolidar-aunque no a crear- la perspectiva de un sistema de partidos en transición. A esto debe sumarse que todas las previsiones sobre el resultado de las elecciones de 1994 no hacen más que augurar una profundización de ese cuadro descrito. Entre las expresiones más señaladas de este proceso podrían citarse: la crisis del voto caultivo y de las influencias culturales que lo informaban; la modificación -aún en ciernes, pero con innegable potencialidad-de las pautas de productividad política; las presiones - por cierto mucho más amortiguadas que en la América Latina de "los Fujimori"- en la dirección de una renovación en los sistemas de liderazgo; el crecimiento electoral de la izquierda, que unido a la volatilidad y autonomía de la opinión pública, aumenta la incertidumbre de los futuros arbitrajes ciudadanos; etcétera.

Si el clima político de estos últimos años también pareció ganado por una cierta decepción y atonía (o tal vez por el tedio característico de las postransiciones), un parsimonioso y espasmódico debate de la reforma política ha ido desarrollándose aunque con poco éxito. Condicionado por los "posicionamientos" de la inminente elección de noviembre de 1994, el mismo se ha focalizado en las áreas sensibles del régimen de gobierno, el sistema electoral y el funcionamiento del sistema de partidos. Luego de un trámite tan azaroso como desgastante, el proceso de reforma constitucional ha terminado en un nuevo fracaso categórico, sin que en ningún momento la ciudadanía se haya sentido partícipe de ningún "clima constituyente". Este fracaso, refrendado además por un abrumador rechazo plebiscitario, ha profundizado la constatada percepción pública sobre la presunta inoperancia del sistema político. Más allá de la justicia última de este aserto y de si eso significa la llegada al país de ese fenómeno universal de "reacción antipolítica", lo cierto es que el bloqueo de la reforma política (en sus múltiples dimensiones no sólo constitucionales) puede dificultar el encuentro de los mecanismos institucionales para responder 
con políticas renovadas y de largo plazo a los desafios de este fin de siglo.

En resumidas cuentas, el cuadro político y social del Uruguay de los últimos años presenta a distintos niveles dos constataciones centrales: la primera, que el país se halla ante una encrucijada de cambios al parecer impostergables; la segunda, que los caminos de la mera restauración se encuentran muy limitados y hasta agotados. En este Uruguay de la posdictadura ha existido una fuerte tendencia a percibir a la sociedad como estancada y poco permeable a cualquier tipo de transformación profunda. Si bien ello no autoriza a fundar interpretaciones y proyecciones de mediano y largo plazo, puesta en comparación con otras regiones, la sociedad uruguaya ha ido ambientando en los ámbitos públicos una cierta "cultura de la declinación", cimentada en la percepción recurrente de soportar una crisis cuyos orígenes se remontan a cincuenta años.

De todas formas y en especial ante lo vivido en las últimas dos décadas, Uruguay parece estar lejos del inmovilismo. Pero a pesar de la evidencia de modificaciones muy radicales (tanto positivas como negativas) en los más diversos planos, esta sociedad parece persistir en una conciencia muy insuficiente de sus propios cambios. Como se ha dicho con acierto, Uruguay "suele disimular sus transformaciones". 33

Por ello, tal vez merezcan tenerse presentes como faena de los últimos gobiernos -incluida la dictadura- las medidas de apertura económica, de

33 Pérez, "Partidos", 1993. libertad cambiaria y de capitales que incluso han ambientado una opinión generalizada (pero debatida) en favor de un modelo más abierto. Entre sus múltiples efectos, vastos sectores de la sociedad han incorporado pautas culturales y de consumo internacionales que contrastan además con la persistencia de fuertes desigualdades en la distribución del ingreso. Ello anuncia, y ya hay señales en esa dirección, que, de no mediar amortiguaciones, crece la posibilidad de encontrarnos ante una sociedad más duramente fragmentada.

AlgunOS DESAFÍOS ACTUALES

DE LA POIÍTICA URUGUAYA

Restauración y cambio, tradición y renovación

Como hemos insistido en trabajos recientes, a nuestro juicio el registro de la peripecia histórica y del panorama político actual del país permite identificar dos aspectos sustantivos: a) en primer término, la trascendencia de la matriz política tradicional y de su mayor o menor influjo en el curso más contemporáneo de los procesos políticos; b) en segundo lugar, la constatación -sin duda también extensible a otros países latinoamericanos- de que buena parte de los fenómenos que signan la crisis más actual del sistema político son muchas veces prolongaciones de viejos problemas no resueltos, sin que ello suponga la inexistencia de situaciones auténticamente novedosas y aun inéditas. 
El registro preciso de esa coexistencia dialéctica de "motivos viejos" y fenómenos nuevos en la política uruguaya contemporánea contribuye a disipar cierto "encandilamiento" de las percepciones sólo presentistas. Una perspectiva de análisis historizante - sin historicismo-, respecto a las trayectorias cambiantes de los distintos actores de la política uruguaya, puede coadyuvar a superar algunos de estos problemas.

En esa dirección, lo primero a destacar es que, a nuestro juicio - más allá de los impulsos restauradores y de las reiteradas alusiones al bloqueo-, el sistema político uruguayo se encuentra en la actualidad y desde hace algunos años en un curso de cambio no fácilmente previsible, transformación de la que, por otra parte, forma parte privilegiada el tema de la transición a distintos niveles del funcionamiento de su sistema de partidos.

Como veíamos, la conciencia social en torno a la intensidad de este cambio político ya resulta mucho más ambigua. Para muchos la política uruguaya continúa siendo un terreno dominado por el inmovilismo o el mero restauracionismo, un factor restrictivo al impulso transformador proveniente de otros escenarios o, a lo sumo, una "zona" del acontecer nacional que se limita a recibir - con mayor o menor pasividad y refracción- las iniciativas de cambio originadas en su exterior. Sin embargo, desde la perspectiva del investigador de estos temas, resulta dificil no reparar en la hondura y la multidimensionalidad de los factores involucrados en este pro- ceso de cambio de la política uruguaya. La política uruguaya está cambiando más allá del bloqueo persistente a los proyectos de reforma constitucional e incluso de la propia voluntad de algunos de sus principales actores. Es el sistema político en su conjunto $(y$ no sólo algunos de sus actores y estructuras) y hasta las propias dimensiones y especificidades del "hacer política" lo que está en curso de transformación.

Sin embargo, como ya ha sido dicho, estas modificaciones en la política uruguaya no parecen asociarse con la capacidad autorreformadora del sistema y de sus actores. Tampoco con la ruptura o la interrupción del influjo persistente de muchos de los patrones tradicionales de la cultura política nacional. Es así que la reestructuración política en curso, a distintos niveles, se encuentra atravesada por una tensión peculiar entre renovación y tradición, reeditándose, por otra parte, un fenómeno que siempre ha sido característico de los periodos de cambio en la historia uruguaya. ${ }^{34}$

La persistencia de este influjo - no uniforme por cierto, más menguado en algunos casos, más visible en otros-de pautas y patrones de la vieja formación política uruguaya, no significa en modo alguno que se facilite el camino de la restauración. Por cierto que más que orientar a la restauración, lo que hace la permanencia de ciertos parámetros de la vieja cultura

34 A cste respecto podría citarse el cjemplo clásico del periodo del llamado "primer batllismo". 
política es condicionar - con fuerza en algunos casos- el modo de cambiar. ${ }^{35}$

\section{La transición del sistema de partidos y su curso electoral}

Tal vez uno de los fenómenos más definitorios dentro de ese proceso de reestructuración política en curso sea precisamente la ya aludida transición del sistema de partidos. Más allá de la reconstitución de su centralidad luego de la dictadura, el sistema uruguayo de partidos presenta en la actualidad un conjunto de fenómenos y perfiles que lo colocan claramente en esa dirección transicional. En mayor o menor medida, todos los partidos uruguayos están desafiados hoy por un trance de renovación insoslayable, lo que se vincula con un amplio espectro de cambios a distintos niveles: en sus lógicas de liderazgo, en sus modalidades de resolución política, en sus relaciones con la ciudadanía y con los distintos actores sociales, en el manejo de sus tensiones internas.

Se profundiza la crisis de las inercias keynesianas en el funcionamiento partidario (con sus perdurables dispositivos distributivos y clientelares), pasándose gradualmente $-\mathrm{y}$ con dificultades- hacia la construcción de partidos "de ciudadanía" o "de opinión", más aptos para la producción de políticas generales. En un sistema como el uruguayo en el que tradicionalmente los partidos han sido los

35 Esta pauta podría también prolongarse a muchos de los procesos de renovación que actualmente se están dando dentro de casi todos los partidos uruguayos. principales actores de gobierno, estas modificaciones cobran una significación especialísima.

Tal vez sea el escenario electoral un campo privilegiado para observar la entidad y el curso incierto de los cambios partidarios en el Uruguay de la posdictadura. A contramano de pautas tradicionales de estabilidad-que se mantuvieron como vimos en las elecciones de 1984-, los últimos comicios nacionales de 1989 significaron una verdadera conmoción en los comportamientos de la ciudadanía: baste citar a este respecto la victoria nacionalista que viabilizó la rotación de los partidos en el gobierno, la derrota estrepitosa del Partido Colorado, el crecimiento vigoroso de la izquierda que obtiene el gobierno municipal en la capital Montevideo, la consolidación de un cuadro multipartidista, la acelerada variación de las hegemonías electorales en el interior de los lemas, etcétera.

La crisis del voto cautivo y la confirmación de una volatilidad importante a nivel de opinión pública han acrecentado a niveles inéditos en el país la competitividad política y el carácter cambiante en la marcha del sistema de partidos. Por su parte, durante este año electoral las encuestas de opinión vienen revelando un cuadro de intención de voto con perfiles volátiles y el anuncio de modificaciones todavía más profundas respecto a los resultados de los últimos comicios. En esa misma línea, todo parece indicar que el partido ganador de los próximos comicios estará lejos de tener mayoría en el Parlamento y que las negociaciones para obtener un gobierno 


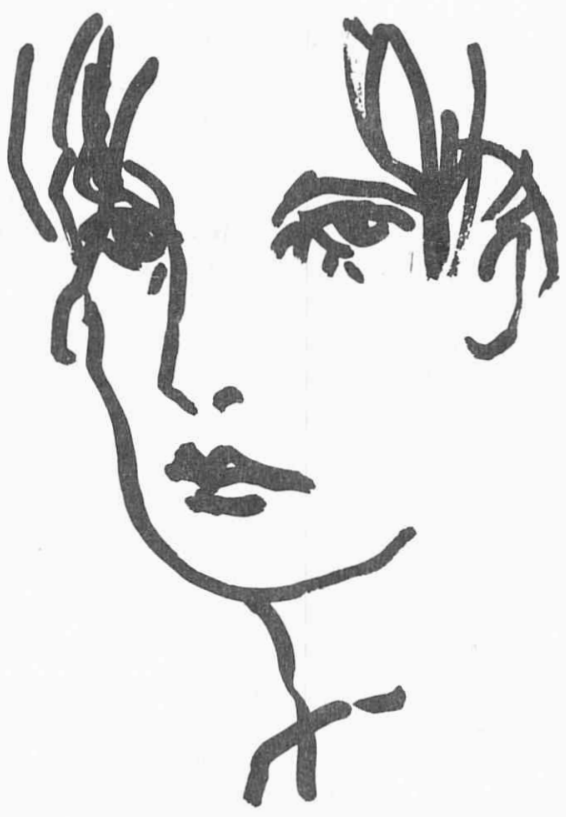

con respaldo parlamentario sólido habrán de ser especialmente arduas.

De cara a los próximos comicios de noviembre se han producido también algunas novedades de importancia en lo que tiene que ver con la constelación de los actores en competencia. Por un lado y luego de un complejo proceso, finalmente se ha concretado el acuerdo electoral del Partido por el Gobierno del Pueblo (PGP) con el sector mayoritario del Partido Colorado, el llamado Foro Batllista, liderado por el ex presidente, el doctor Julio $\mathrm{M}$. Sanguinetti. Al no haberse reformado la Constitución, este acuerdo político respalda la candidatura presidencial del doctor Sanguinetti dentro del lema "Partido Colorado", en el que además aparecen otras dos candidaturas presidenciales (del ex presidente Jorge Pacheco Areco y del doctor Jorge Batlle). Por su parte, la coalición de izquierdas Frente Amplio ha establecido también un acuerdo electoral con el Partido Demócrata Cristiano y sectores escindidos del Partido Nacional y del PGP, respaldando todas estas fuerzas la candidatura presidencial del ex intendente de Montevideo doctor Tabaré Vázquez dentro del llamado "Encuentro Progresista". Completan el cuadro partidario electoral el gobernante Partido Nacional (con tres candidaturas presidenciales, las de los doctores Volonté y Ramírez y el profesor Carlos Julio Pereira) y un conjunto diverso de partidos y formaciones menores.

Más allá de sus asimetrias internas y del respaldo ciudadano efectivo que 
obtengan en las urnas, estas dos nuevas experiencias coalicionistas antes citadas plantean una novedad en verdad relevante dentro del sistema de partidos. Todavía es muy pronto para evaluar si ambas formaciones perdurarán luego de los comicios de noviembre, pero su simple configuración perfila sin duda el mapa de los posicionamientos partidarios de los próximos años.

No resulta aventurado entonces identificar un sistema de partidos en transición que, al tiempo que recobra su centralidad, ingresa en un proceso de transformación signado por un margen importante de incertidumbre. En ese marco, empero, los cambios que se avizoran no parecen demostrar el talante dramático que se observa en otras partes del continente: por ejemplo, no parece haber espacio aún para "fujimorismos" o experiencias similares. Pese a que la redefinición de lo social -más allá de las apariencias- es intensa y que los procesos de fragmentación plantean fuertes desafios para la integración política y programática, pese a que las señales de desencanto ante la política se multiplican y llegan hasta la propia elite política, los partidos tampoco parecen enfrentar - por lo menos hasta el momento en que se escriben estas líneas- la amenaza de que actores extrapartidarios les disputen espacios fundamentales. Ciertamente que el sistema de partidos ha cedido parte de las funciones que otrora se reservaba y que sus acciones tal vez "entusiasman" bastante menos que antes, pero todavía mantiene un conjunto de "haberes" y posibilidades que no parecen augurar -con todo lo arriesgadas que son las "predicciones" en estos tiempos de incertidumbre- alteraciones traumáticas al menos en el corto plazo.

Sin embargo, si los desenlaces traumáticos o los virajes espectaculares no son todavía pronosticables en la política uruguaya de hoy, el cuadro de incertidumbres amenaza profundizarse en el futuro más próximo. Los pronósticos en cuanto a las modalidades posibles de articulación entre partidos y electores parecen abonar esa hipótesis. Como se ha señalado, los partidos evidencian una creciente disminución de su credibilidad al nivel de la opinión pública, al tiempo que se vuelve cada vez más visible el debilitamiento de sus aparatos tradicionales de intermediación política. Por su parte, el electorado se manifiesta cada vez más autónomo e inestable en sus comportamientos, mientras se profundiza a nivel general el desinterés por la política. Todo esto no hace más que agregar imprevisibilidad a un sistema político que tradicionalmente ha ostentado una estabilidad casi "aburrida".

A este respecto, ha señalado Pablo Mieres:

El resultado electoral de 1989 marcó [...] cambios significativos que ya no provinicron fundamentalmentc de los actores partidarios - que en esta instancia ofrecicron pocas novedades respecto a 198 - sino del clectorado. $\Lambda$ sí podría afirmarse que el caso uruguayo evolucionó en 1989 hacia el realinciamiento de los electores. Fisto significa que los electores habrian variado su estructura de preferencias, rompiendo con sus lealtades básicas anteriores, con independencia de la oferta particla- 
ria; el motor del proceso de transformación electoral se sitúa en las decisiones de la ciudadanía que quiebra o relativiza sus anteriores alineamientos políticos. [...] Si los impulsos partidarios se conjugan con la inestabilidad de los electores, el cuadro de situación del sistema político uruguayo se aproximará en 1994 a lo que Rose y McAllister denominaron situación de completo desalineamiento, donde tanto los partidos como los electores expresan inestabilidad. [...] Si el sistema político uruguayo cuenta con esa doble situación de inestabilidad $[\ldots]$ deberá admitirse, más allá de qué partido y candidato gane la elección de 1994, que los procesos de transformación y reestructuración $[\ldots]$ iniciados hace más de tres décadas se prolongarán al menos por un tiempo más.

\section{Algunos de los desafios de la agenda más actual}

El simple registro de algunos de los desafios más importantes que enfrenta la política uruguaya contemporánea perfila no pocas paradojas. Se trata de un sistema político en curso de reestructuración visible, pero que no revela capacidades para impulsar una reforma autorregulada de sus reglas de juego. Se trata de la transición también manifiesta de los actores políticos y sociales que, sin embargo, en sus desempeños siguen reproduciendo muchas de las viejas lógicas de la formación tradicional. Es un sistema político que presenta una erosión creciente de sus capacidades y posibilidades, pero al que se sigue hiperresponsabilizando por omisión o por delegación. Es una sociedad en la que sobresale la apelación recurrente al compromiso integrador en el Mercosur, pero también el no menos reiterado escepticismo a la hora de arriesgar a favor de la reconversión. Se trata, finalmente, de una ciudadanía que desde hace décadas viene sancionando a los gobiernos y demostrando una proclividad de veto ante las iniciativas de cambio demasiado audaces, que sin embargo no se muestra igualmente activa y decidida a la hora de elegir o respaldar propuestas alternativas.

Tal vez el gran malestar colectivo que se expresa en todas estas contradicciones y en los signos crecientes de desinterés por la política y por lo público tenga que ver también con un tema que alude directamente a la problemática central de este seminario. En esta dirección la interrogante planteada apunta a debatir sobre si los partidos uruguayos se encuentran efectivamente en condiciones de transformarse a fin de ser capaces de expresar y de dar respuesta a las tensiones y dilemas de la coyuntura más actual. El aceleramiento de los cambios mundiales de toda índole en la última década y la consolidación del involucramiento del país en la región (que no empezó ni por cierto terminará con el Mercosur) no han hecho más que profundizar la hondura de los desafíos que tienen ante sí los partidos y la urgencia de no demorar respuestas apropiadas ante los mismos.

Muchas de las circunstancias principales del proceso político más reciente revelan también un importante déficit de tramitación política de los "asuntos" más relevantes de la sociedad uruguaya actual. Con las fuertes restricciones que se imponen actual- 
mente a una contienda responsable de iniciativas de gobierno y en el marco de una confrontación programática centrípeta y bastante light, existen sin embargo bloqueos muy considerables para la instalación de "políticas de Estado" en algunas áreas de interés estratégico. Aun cuando ese tipo de acuerdos (a veces rígidos) no siempre es la mejor opción para un país con problemas de arbitrajes dinámicos para iniciativas de corto plazo como el Uruguay, las dificultades para su concreción evidencian sin duda obstáculos de tramitación política de la agenda ciudadana.

Sin sociocentrismos fáciles y voluntaristas, cualquier empeño que pretenda formular una alternativa viable en la perspectiva de un desarrollo innovador no podrá desentenderse del tópico de la renovación de estos aspectos de la vida política. La falta de productividad política y simbólica del sistema de partidos constituye en definitiva un asunto de capital importancia en el tema que nos ocupa. Aun acordes con una apuesta de recolocación y desresponsabilización de la política en la convivencia cotidiana de los uruguayos, dificilmente en la construcción del país del futuro - cualquiera sea el signo de éste-se podrán saltar estos temas.

Son los propios fundamentos de la política nacional, de la reproducción de nuestra convivencia cívica, de la siempre problemática sustentación de un "espacio público" 36 los que se hallan bajo una presión que no debe minimizarse. No

36 Utilizamos aquí la categoría de "espacio público" como el ámbito de resonancia de to- sólo porque el pacto de inspiración keynesiana y el aún más antiguo "Uruguay del primer batllismo" ya no admiten restauraciones o prolongaciones lineales, sino también porque la impaciencia y el escepticismo respecto de la eficacia del régimen democrático han reaparecido en el país.

No debe confundirse la sólida firmeza de las convicciones democráticas en la masa de los uruguayos con la imposibilidad de deslizamientos mesiánicos, delegacionistas o francamente autoritarios. La atención preocupada a las raíces del Estado pluralista no resulta hoy antojadiza ni apresurada, mucho más si de lo que se trata es de analizar las bases de un nuevo modelo de desarrollo a la altura de estos tiempos.

Después de todo, las exigencias de este fin de siglo y las herencias todavía vigentes de una cultura política refinada y espesa como la uruguaya no permiten concebir agendas simples. Cualquier camino que se insinúe en la dirección del cambio podría ya incorporar las cuestiones no sólo referidas a "qué cambiar" sino también a "cómo cambiar". En ese marco, una vez más, lo que ocurra en relación con los partidos pólíticos será de fundamental relevancia para el futuro de la sociedad uruguaya.

\section{BIBLIOGRAFÍA}

-Barrán, José P. y Benjamín Nahúm, Batlle, los estancieros y el gobiemo briláni$\mathrm{co}, 8$ vols.

das las voces de una sociedad y foro de controversias que preparan la regulación legítima de las cuestiones más urgentes y generakes. 
- Caetano, Gerardo, "Partidos, estados y cámaras empresariales en el Uruguay contemporáneo (1900-1991)" en Varios, Organizaciones empresariales y políticas públicas, PESUR-LOgOS, Montevideo, 1992.

-Caetano, Gerardo y Raúl Jacob, El nacimiento del terrorismo (1930-1933), EBo, Montevideo, 1989.

-Caetano, Gerardo y José Rilla, "El sistema de partidos, raíces y permanencias" en Varios, De la tradición a la crisis. Pasado y presente de nuestro sistema de partidos. ClanH-EBo, Montevideo, 1985.

- Breve historia de la dicladura (1973-1985), ClaEn-EBO, Montevideo, 1987 (Argumento, 10).

__ _ "El movimiento sindical y 'el proceso'. Los fracasos de la dictadura”, en Notas del CLAEH-EBO, núm. 53, Montevideo, junio de 1988.

- "La partidocracia uruguaya en busca de un espejo. Partidos, Estado y sociedad civil en Río de la Plata (18901930)" en Los partidos políticos en el Río de la Plata, Cuadernos del CLAEH, núm. 50, Montevideo, 1989/2.

— "Historia contemporánea del Uruguay. De la Colonia al Mercosur", Fin de Siglo, ClaEh, Montevideo, 1994.

-Caetano, Gerardo, José Rilla y Romeo Pérez, "La partidocracia uruguaya. Historia y teoría de la centralidad de los partidos políticos", Cuadernos del CLAEII, núm. 44, Montevideo, 1987/4.

lios en el sistema político uruguayo concebido como una partidocracia", en Varios, Los partidos políticos de cara al 90, Instituto de Ciencia Política FESUR, Montevideo, 1989.

- Cactano Gerardo, José Rilla, Pablo Mieres y Romco Pérez, Parlidos electores. Centralidad y cambios, CLAFII-EBO, Montevideo, 1992 (Argumentos, 17).

- Easton David, Esquema para el análisis polílico, Amorrortu, Buenos Aires, 1979.
-Filgueira, Carlos, Organizaciones sindicales y empresariales ante las politicas de estabilización: Uruguay 19851987, ciesu, Montevideo, 1988.

-Lanzaro, Jorge Luis, "Los empresarios en la democracia restaurada” (mimeografiado).

- Neocorporativismo y democracia en el capitalismo contemporáneo, ClaEII, Montevideo, 1987.

— , "Estado y política en el Uruguay postautoritario", en Varios, Propuestas polílicas, comportamientos electorales y perspectivas de gobiemo en el Cono Sur, OBsur, Montevideo, 1990.

-Panizza, Francisco, Uruguay; ballismo y después, Pacheco, mililares y tupamaros en la crisis del Uruguay ballista, EBO, Montevideo, 1990.

- "Poder estructural y hegemonía: Estado y ganaderos en la década del 60", Revista de Ciencias Sociales, núm. 3, Montevideo, 1988.

-Panizza, Francisco y Adolfo Pérez Picera, Estado y sociedad, FESUR-FCEU, Montevideo, 1988.

-Pérez Romeo, "Cuatro antagonismos sucesivos. La concreta instauración de la democracia uruguaya", Revista de Ciencia Política, núm. 2, FCU, Montevideo, 1988.

, "Partidos y demandas de actores sociales en el Mercosur. El caso uruguayo", CLAfi, Montevideo, 1993 (mimeografiado).

-Rama, Germán, La democracia en Uruguay, GLL-RIAL, Buenos Aires, 1987.

- Real de Azúa, Carlos, Uruguay: ¿Una sociedad amortiguadora? CIESU-FiBO, Montevideo, 1984.

-Stolovitch Luis y Juan Manuel Rodríguez, "Gobicrno y empresarios: sus vínculos personales", en Varios, ¿Hacia dónde va el Eslado uruguayo? Concentración de poder y democracia, CIEIJUR-IiCu, Montevideo, 1987. 